\title{
Front Matter: Volume 10644
}

, "Front Matter: Volume 10644," Proc. SPIE 10644, Algorithms and Technologies for Multispectral, Hyperspectral, and Ultraspectral Imagery XXIV, 1064401 (17 July 2018); doi: 10.1117/12.2501995

SPIE. Event: SPIE Defense + Security, 2018, Orlando, FL, United States 


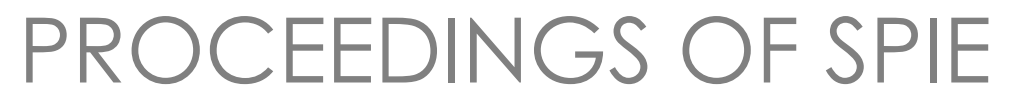

\section{Algorithms and Technologies for Multispectral, Hyperspectral, and Ultraspectral Imagery XXIV}

Miguel Velez-Reyes

David W. Messinger

Editors

17-19 April 2018

Orlando, Florida, United States

Sponsored and Published by

SPIE

Volume 10644 
The papers in this volume were part of the technical conference cited on the cover and title page. Papers were selected and subject to review by the editors and conference program committee. Some conference presentations may not be available for publication. Additional papers and presentation recordings may be available online in the SPIE Digital Library at SPIEDigitallibrary.org.

The papers reflect the work and thoughts of the authors and are published herein as submitted. The publisher is not responsible for the validity of the information or for any outcomes resulting from reliance thereon.

Please use the following format to cite material from these proceedings:

Author(s), "Title of Paper," in Algorithms and Technologies for Multispectral, Hyperspectral, and Ultraspectral Imagery XXIV, edited by Miguel Velez-Reyes, David W. Messinger, Proceedings of SPIE Vol. 10644 (SPIE, Bellingham, WA, 2018) Seven-digit Article CID Number.

ISSN: 0277-786X

ISSN: 1996-756X (electronic)

ISBN: 9781510617995

ISBN: 9781510618008 (electronic)

Published by

SPIE

P.O. Box 10, Bellingham, Washington 98227-0010 USA

Telephone +1 3606763290 (Pacific Time) · Fax +1 3606471445

SPIE.org

Copyright (C) 2018, Society of Photo-Optical Instrumentation Engineers.

Copying of material in this book for internal or personal use, or for the internal or personal use of specific clients, beyond the fair use provisions granted by the U.S. Copyright Law is authorized by SPIE subject to payment of copying fees. The Transactional Reporting Service base fee for this volume is $\$ 18.00$ per article (or portion thereof), which should be paid directly to the Copyright Clearance Center (CCC), 222 Rosewood Drive, Danvers, MA 01923. Payment may also be made electronically through CCC Online at copyright.com. Other copying for republication, resale, advertising or promotion, or any form of systematic or multiple reproduction of any material in this book is prohibited except with permission in writing from the publisher. The CCC fee code is 0277$786 \mathrm{X} / 18 / \$ 18.00$.

Printed in the United States of America.

Publication of record for individual papers is online in the SPIE Digital Library.

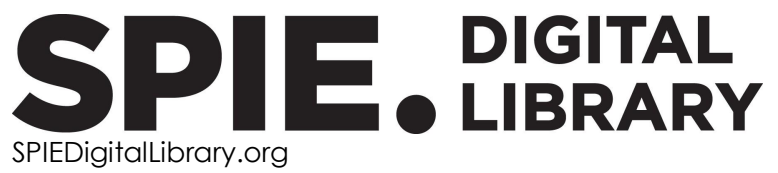

Paper Numbering: Proceedings of SPIE follow an e-First publication model. A unique citation identifier (CID) number is assigned to each article at the time of publication. Utilization of CIDs allows articles to be fully citable as soon as they are published online, and connects the same identifier to all online and print versions of the publication. SPIE uses a seven-digit CID article numbering system structured as follows:

- The first five digits correspond to the SPIE volume number.

- The last two digits indicate publication order within the volume using a Base 36 numbering system employing both numerals and letters. These two-number sets start with $00,01,02,03,04$, $05,06,07,08,09,0 A, 0 B \ldots$. OZ, followed by 10-1Z, 20-2Z, etc. The CID Number appears on each page of the manuscript. 


\title{
Contents
}

\author{
ix Authors \\ xi Conference Committee \\ xiii Introduction
}

TARGET AND ANOMALY DETECTION

1064402 Target detection using artificial neural networks on LWIR hyperspectral imagery [10644-1]

1064403 Impact of plafform motion on hyperspectral imaging target detection and ground resolution distance [10644-3]

1064404 A machine learning approach to hyperspectral detection of solid targets [10644-4]

1064405 Onboard CubeSat data processing for hyperspectral detection of chemical plumes [10644-5]

1064406 Closed-form solutions to replacement target models of sub-pixel spectral detection [10644-6]

\section{DIMENSIONALITY REDUCTION AND FEATURE EXTRACTION}

1064407 Optimal sensor control for fast target detection in hyperspectral imagery [10644-7]

1064408 Semi-supervised normalized embeddings for land-use classification from multiple view data [10644-8]

1064409 Dimensionality reduction for spatial-spectral target detection on hyperspectral imagery [10644-9]

$106440 \mathrm{~A}$ Using a column subset selection method for endmember extraction in hyperspectral unmixing [10644-10]

\section{IMAGE FUSION}

$10644 \mathrm{OB}$ On the generation of high-spatial and high-spectral resolution images using THEMIS and TES for Mars exploration [10644-11]

10644 OC Spectral-elevation data registration using visible-SWIR spatial correspondence [10644-12] 
10644 OD Landing zone identification for autonomous UAV applications using fused hyperspectral imagery and LIDAR point clouds [10644-13]

\section{MACHINE LEARNING IN SPECTRAL SENSING}

10644 OF A study of the effect of alternative similarity measures on the performance of graph-based anomaly detection algorithms (Invited Paper) [10644-20]

10644 OG Threat determination for radiation detection from the Remote Sensing Laboratory (Invited Paper) [10644-16]

$10644 \mathrm{OH} \quad$ Scattering transforms and classification of hyperspectral images (Invited Paper) [10644-17]

$10644 \mathrm{Ol} \quad$ Diffusion geometric methods for fusion of remotely sensed data (Invited Paper) [10644-18]

10644 OK Semi-supervised deep autoencoder network for graph-based dimensionality reduction of hyperspectral imagery [10644-15]

\section{PERFORMANCE EVALUATION OF SENSORS AND SYSTEMS}

$10644 \mathrm{OL} \quad$ Examining the impact of spectral uncertainty on hyperspectral data exploitation [10644-21]

10644 ON Evaluating calibration consistency of Terra and Aqua MODIS LWIR PV bands using Dome C [10644-23]

$1064400 \quad$ Evaluating the long-term stability and response versus scan angle effect in the SNPP VIIRS SDR reflectance product using a deep convective cloud technique [10644-24]

10644 OP Simulation techniques for image utility analysis [10644-25]

$106440 Q$ A computational approach to hyperspectral imaging for long-range target identification [10644-26]

\section{ATMOSPHERIC MODELING AND COMPENSATION}

10644 OR Sensitivity of temperature and emissivity separation to atmospheric errors in LWIR hyperspectral imagery [10644-27]

10644 OT Seeing through heavily polluted satellite imagery using QUAC [10644-29]

$10644 \mathrm{OU} \quad$ Atmospheric correction of commercial thermal infrared hyperspectral imagery using FLAASHIR [10644-30] 
LWIR AND MWIR SPECTRAL SENSING

10644 OV Comparison of bad pixel replacement techniques for LWIR hyperspectral imagery [10644-31]

10644 OW Infrared signature measurements of a jet turbine using a hyperspectral imager for combustion diagnostics [10644-32]

10644 OX Design, calibration and characterization of a low-cost spatial Fourier transform LWIR hyperspectral camera with spatial and temporal scanning modes [10644-33]

10644 OY Infrared absorption bands measured with an uncooled interferometric LWIR hyperspectral camera [10644-34]

\section{CHANGE DETECTION AND IMAGE REGISTRATION}

$10644 \mathrm{OZ} \quad$ High performance change detection in hyperspectral images using multiple references [10644-35]

1064410 A new nonlinear change detection approach based on band ratioing [10644-36]

$1064411 \quad$ Multi-spectral change detection methods: evaluation on simulated and real-world satellite imagery [10644-37]

1064412 Temperature-robust longwave infrared hyperspectral change detection [10644-38]

$1064413 \quad$ Image registration and change detection for artifact detection in remote sensing imagery [10644-39]

1064414 Improvement of the Harris corner detector using an entropy-block-based strategy [10644-40]

\section{APPLICATIONS}

$1064415 \quad$ Pigment diversity estimation for hyperspectral images of the Selden map of China [10644-41]

$1064416 \quad$ Necessary steps for the systematic calibration of a multispectral imaging system to achieve a targetless workflow in reflectance estimation: a study of Parrot SEQUOIA for precision agriculture [10644-42]

$1064418 \quad$ Multispectral imaging for improved liquid classification in security sensor systems [10644-44] 
SENSOR, DESIGN, DEVELOPMENT, AND CHARACTERIZATION

10644 1B Three mirror off-axis optical system with an obscuration hole as a fore optics of the hyperspectral imager [10644-47]

10644 ID A compressive approach to imaging spectroscopy [10644-49]

$10644 \mathrm{IE} \quad$ Agile optoelectronic fiber sources for hyperspectral chemical sensing from SWIR to LWIR [10644-50]

$10644 \mathrm{IF} \quad$ Measurement of point spread function for characterization of coregistration and resolution: comparison of two commercial hyperspectral cameras [10644-51]

$106441 G$ Compact visible to extended-SWIR hyperspectral sensor for unmanned aircraft systems (UAS) [10644-52]

\section{SPECTRAL MODELING AND CHARACTERIZATION}

$1064411 \quad$ Grazing angle experimental analysis of modification to microfacet BRDF model for improved accuracy [10644-54]

$106441 \mathrm{~J} \quad$ Case-study analysis of apparent color for camouflage fabrics [10644-55]

$10644 \mathrm{~K} \quad$ Influence of surface roughness, volume diffusion and particle size in reflectance infrared spectroscopy [10644-56]

$10644 \mathrm{lL} \quad$ Measurement campaign for hyperspectral imaging in complex illumination environments [10644-58]

\section{POSTER SESSION}

10644 IM A new bandwidth selection criterion for using SVDD to analyze hyperspectral data [10644-60]

10644 IN Statistical evaluation of the periodically sampled method for efficient measurement of the distortions in hyperspectral imager [10644-62]

$1064410 \quad$ Programmable system on chip implementation of a principal component analysis for preprocessing of multispectral image data acquired with filter wheel cameras [10644-63]

$106441 Q \quad$ Noise reduction for improving the performance of gas detection algorithms in the FTIR spectrometer [10644-65]

10644 IR A wide dense architecture neural network for material classification based on spectral BTF [10644-66]

10644 is Advanced imaging system with multiple optical sensing modes [10644-67] 
10644 IT Parametric modeling of NIR and SWIR reflectance spectra for dye mixtures in fabrics using reference spectra [10644-68]

$106441 \mathrm{U} \quad$ Evaluation of MODIS and Sentinel-3 SLSTR thermal emissive bands calibration consistency using Dome C [10644-69]

$10644 \mathrm{lV} \quad$ Comparative study of spectral matched filter, constrained energy minimization, and adaptive coherence estimator for subpixel target detection based on hyperspectral imaging [10644-70]

10644 IW Processes for conducting HSI and MSI pan-sharpening with 3D digital flattening [10644-71]

10644 1X Evaluation of the on-orbit response versus scan-angle (RVS) performance for the MODIS reflective solar bands using multiple ground targets [10644-72]

$1064412 \quad$ Underwater target detection with hyperspectral imagery for search and rescue missions [10644-74]

1064420 Spectral phenomenology of historical parchments and inks to aid cultural heritage imaging system development [10644-75]

$1064421 \quad$ Seeded Laplacian in sparse subspace for hyperspectral image classification [10644-76]

1064422 Low-dimensional enhanced superpixel representation with homogeneity testing for unmixing of hyperspectral imagery [10644-77]

1064423 Toward an AR multiperspective active imaging environment for application development [10644-78]

$1064427 \quad$ Kernel PCA for anomaly detection in hyperspectral images using spectral-spatial fusion [10644-83]

1064428 Modeling apparent camouflage patterns for visual evaluation [10644-84] 
Proc. of SPIE Vol. 10644 1064401-8

Downloaded From: https://www.spiedigitallibrary.org/conference-proceedings-of-spie on 25 Apr 2023 Terms of Use: https://www.spiedigitallibrary.org/terms-of-use 


\title{
Authors
}

Numbers in the index correspond to the last two digits of the seven-digit citation identifier (CID) article numbering system used in Proceedings of SPIE. The first five digits reflect the volume number. Base 36 numbering is employed for the last two digits and indicates the order of articles within the volume. Numbers start with 00, 01, 02, 03, 04, 05, 06, 07, 08, 09, OA, OB...0Z, followed by 10-12, 20-2Z, etc.

\author{
Aberra, Dawit, 21 \\ Adler-Golden, Steven, OT, OU \\ Albota, Marius, $1 \mathrm{~L}$ \\ Aldeghlawi, Maher, OA \\ Alsweiss, S., 23 \\ Angal, Amit, 1U, 1X \\ Ash, Joshua N., 12 \\ Axelsson, Linnea, OX \\ Ayhan, Bulent, OB, 10 \\ Azevedo, David, OW \\ Bai, Di, 15 \\ Bajwa, Waheed U., 18 \\ Bergström, David, OX \\ Bernstein, Lawrence, OT \\ Bhargava, Rohit, 1E \\ Biggar, Stuart, 1L \\ Budavari, Bence, OB \\ Burns, Andrea, 18 \\ Butler, Samuel D., 11 \\ Cahill, Nathan D., 08, OK \\ Carney, P. Scott, $1 \mathrm{E}$ \\ Carr, Domenic, OD \\ Castaneda, Giorgy, OB \\ Cathcart, M., 23 \\ Chang, Tiejun, 00 \\ Chaudhuri, Arin, 1M \\ Chilenski, Mark, 07 \\ Choi, Byeongin, 1B, 1N \\ Chou, Bryan, OB \\ Cooley, T., OR \\ Czaja, Wojciech, $\mathrm{OH}$ \\ Diaz, E., $1 \mathrm{~K}$ \\ Dickenshied, Scott, OB \\ Didier, Chris, 23 \\ Dinu, Mihaela, 1E \\ Domenzain, L. M., 16 \\ Dong, Chunhua, 21 \\ Doster, T., OF, 27 \\ Durkee, Nicholas, 12 \\ Echavarren, Adam, OB \\ Eken, İsa Cem, 12 \\ Emerson, T. H., OF \\ Ewing, Becca E., 11 \\ Fallet, C., 16 \\ Fletcher, Ian, $1 \mathrm{~L}$ \\ Ford, William P., OG \\ Fox, M., $1 G$ \\ Foy, Bernard R., 05 \\ French, Rebecca, 1D
}

Fridlund, Martin, OX

Fung, Ping, $1 \mathrm{~L}$

Fütterer, Richard, 10

Gartley, Michael, IR

Geng, XU, $1 X$

Georgan, Chelsea, 07

Gigan, Sylvain, 1D

Goldstein, N., $1 G$

Golowich, Steven, $1 \mathrm{~L}$

Grant, Andrew, 1E

Gross, Kevin, OW

Guler, Nevzat, OU

Gulley, Charles, $1 \mathrm{~L}$

Gurjar, Rajan, 1L

Haberle, Christopher, OB

Hague, Emma, OG

Hallberg, Tomas, OX, OY

Han, Sanghui, OP

Held, Elizabeth L., 13

Henderson, John R., 13

Hendricks, Leif, $1 \mathrm{~S}$

Higbee, Shawn, OP

Hong, Jinsuk, 1B, 1N

Howell, David, 15

Howells, C., 28

Humphreys, David, $0 Q$

Ientilucci, Emmett, 14

Immel, Poppy G., 08

Ingle, $V .$, OR

Integlia, R., 23

Islas, Genesis, OV

Jacobson, John, OR, $1 \mathrm{~L}$

James, Ryan, OD

Jaques, James, $1 \mathrm{E}$

Jiang, Hansi, $1 M$

Jnawali, Kamal, IV

Kakde, Deovrat, 1M

Kang, Inuk, $1 \mathrm{E}$

Kaufman, Jason R., 09

Kavalerov, llya, $\mathrm{OH}$

Kerekes, John P., OP, 11, 1V

Kim, Yeonsoo, 1B, 1N

Kim, Youngsoo, 1B, 1N

Kira, Zsolt, OD

Klein, Sarah, 1L

Kong, Seunghyun, 1M

Kucer, Michal, 04

Kunns, Tyler, 20

Kwan, Chiman, OB, OZ, 10 
Lamb, Robert A., $0 Q$

Lambrakos, S. G., 1J, 1T, 28

Lane, Sarah, OD

Lee, Jae-Hoon, $1 Q$

$\mathrm{Li}$, Weilin, $\mathrm{OH}$

Liao, Yuwei, $1 \mathrm{M}$

Lockwood, Ronald, $1 \mathrm{~L}$

Love, Steven P., 05

Maggioni, Mauro, 01

Manolakis, D., OR

Marciniak, Michael, OW

Martin, Jacob A., 02, OV

Mathew, Jobin J., 11

Mayo, T., 1J, 1T, 28

McCormick, Kyle, is

McCullough, Tom, OG

Meinhold, R. T., 27

Meola, Joseph, 03, 09, OL, 12

Messinger, David W., 15, 1W, 20

Moore, Eric, OG

Mu, Qiaozhen, 00, $1 \mathrm{X}$

Murphy, Cara, 07

Murphy, James M., 이

Muskens, Otto L., 1D

Nadile, Richard, 1L

Naghedolfeizi, Masoud, 21

Nakanishi, K., $1 G$

Nam, Hyun-Woo, $1 Q$

Nascimento, Jaclyn M., is

Nichols, Luke J., 23

Notni, Gunther, 10

Olson, C. C., OF, 27

Ortiz, Anthony, OC

Park, Byeong-Hwang, $1 Q$

Park, Dong-Jo, 1Q

Paulec, Mason, OW

Peery, Tyler R., IW

Perkins, Timothy, OU

Pfister, Luke, IE

Pieper, M. L., OR

Prine, J., 23

Qiu, Hao, 21

Ramsey, S., 1J, 1T, 28

Rao, Navalgund, $1 \mathrm{~V}$

Raz, Gil, 07

Rosario, Dalton, $\mathrm{OC}$

Rosenberger, Maik, 10

Sadek, Carol, $1 \mathrm{M}$

Safi, Claira, 05

Saleh, M., IG

Schaum, Alan, 06

Schellhorn, Mathias, 10

Shabaev, A., 28

Shrestha, Ashish, 0N, 1U

Siegel, Lawrence, OP

Skauli, Torbjørn, 1F

Skelly, Luke, $1 \mathrm{~L}$

Soletsky, P., 1G

St. Peter, Benjamin, ОT

Stowe, Lin, 1L
Sun, Yihang, 14

Svensson, Thomas, OX, OY

Tanner, Jared, $\mathrm{OQ}$

Tannian, Bridget, OT, $1 \mathrm{G}$

Theiler, James, 04, 05

Thériault, J.-M., $1 \mathrm{~K}$

Thompson, Andrew, $0 Q$

Torkildsen, Hans Erling, IF

Truslow, E., OR

Tuell, Grady, OD

Turk, Johanna, OG

Vary, Simon, $0 Q$

Velez-Reyes, Miguel, 0A, 22

Viger, R., $1 T$

Voisin, Sophie, 14

Weingarten, Zachary, 23

Weisner, A., OR

Wiggins, R., $1 G$

Wilson, Truman, ON

Woodman, P., $1 G$

Wu, Aisheng, 0N, 00, 1X

Wurst, Nathan, 03

Xiong, Xiaoxiong, 0N, 00, 1U, 1X

Yang, Gefei, $1 \mathrm{R}$

Yardimci Çetin, Yasemin, $1 Z$

Yi, Jiarui, 22

Yu, Hyeong-Geun, 1Q

Zelinski, Michael E., 13

Zeng, Xiangyan, 21

Zhang, Xuewen, OK

Zhou, Jin, OZ, 10

Ziemann, Amanda, 04

Ziph-Schatzberg, L., 1G 


\section{Conference Committee}

Symposium Chair

Arthur A. Morrish, Raytheon Space and Airborne Systems

(United States)

Symposium Co-chair

Ruth Moser, Air Force Research Laboratory (United States)

Conference Chairs

Miguel Velez-Reyes, The University of Texas at El Paso (United States)

David W. Messinger, Rochester Institute of Technology (United States)

Conference Program Committee

Wojciech Czaja, University of Maryland, College Park (United States)

Michael T. Eismann, Air Force Research Laboratory (United States)

Jacqueline J. Le Moigne, NASA Goddard Space Flight Center (United States)

Joseph Meola, Air Force Research Laboratory (United States)

Daniela I. Moody, Descartes Labs, Inc. (United States)

Dalton S. Rosario, U.S. Army Research Laboratory (United States)

Alan P. Schaum, U.S. Naval Research Laboratory (United States)

Torbjørn Skauli, Norwegian Defence Research Establishment

(Norway)

James Theiler, Los Alamos National Laboratory (United States)

Grady Tuell, 3D Ideas LLC (United States)

Alina Zare, University of Florida (United States)

Session Chairs

1 Target and Anomaly Detection

Miguel Velez-Reyes, The University of Texas at El Paso (United States)

2 Dimensionality Reduction and Feature Extraction

Amanda K. Ziemann, Los Alamos National Laboratory (United States)

3 Image Fusion

Dalton S. Rosario, U.S. Army Research Laboratory (United States)

$4 \quad$ Machine Learning in Spectral Sensing

Wojciech Czaja, University of Maryland, College Park (United States) 
5 Performance Evaluation of Sensors and Systems

Joseph Meola, Air Force Research Laboratory (United States)

6 Atmospheric Modeling and Compensation

John P. Kerekes, Rochester Institute of Technology (United States)

$7 \quad$ LWIR and MWIR Spectral Sensing

Michael T. Eismann, Air Force Research Laboratory (United States)

8 Change Detection and Image Registration

James P. Theiler, Los Alamos National Laboratory (United States)

9 Applications

Emmett J. lentilucci, Rochester Institute of Technology (United States)

10 Sensor, Design, Development, and Characterization

Torbjørn Skauli, Norwegian Defence Research Establishment (Norway)

11 Keynote Session

Daniela I. Moody, Descartes Labs, Inc. (United States)

12 Spectral Modeling and Characterization

David W. Messinger, Rochester Institute of Technology (United States) 


\section{Introduction}

These are the proceedings of the 24th edition of the SPIE conference Algorithms and Technologies for Multispectral, Hyperspectral, and Ultraspectral Imagery. This year the conference included 72 presentations organized in twelve oral sessions and one poster session over three days. In addition, we had two invited sessions: (1) a keynote session by Dr. Joseph B. Evans from DARPA/STO (United States) organized by Dr. Daniela Moody from Descartes Labs, Inc. (United States) and (2) an invited session on Machine Learning in Spectral Sensing organized by Dr. Wojciech Czaja from the University of Maryland, College Park (United States). Our deep thanks to the organizers and the guest speakers for their contributions.

Our conference continues to be one of the most important forums for the spectral remote sensing community since 1994. These proceedings contain 66 papers presented at the conference. Many thanks to the members of the program committee for their efforts in putting together one of our most successful conferences in recent history.

We are looking forward to the 25th anniversary of the conference in Baltimore, Maryland (United States) in 2019. We are planning a special celebration.

Miguel Velez-Reyes David W. Messinger 
Proc. of SPIE Vol. 10644 1064401-14 Downloaded From: https://www.spiedigitallibrary.org/conference-proceedings-of-spie on 25 Apr 2023
Terms of Use: https://www.spiedigitallibrary.org/terms-of-use 